See discussions, stats, and author profiles for this publication at: https://www.researchgate.net/publication/261951233

\title{
Analysis of Recrystallization and Strain-Induced Precipitation on High Nb- and N-Bearing Austenitic Stainless Steel
}

Article in Advanced Materials Research · April 2014

DOI: 10.4028/www.scientific.net/AMR.922.700

\section{CITATIONS}

5 authors, including:

Mariana Beatriz dos Reis Silva

Universidade Federal de São Carlos

12 PUBLICATIONS 25 CitATIONS

SEE PROFILE

Jose Maria Cabrera

Universitat Politècnica de Catalunya

289 PUBLICATIONS 2,658 CITATIONS

SEE PROFILE
J. Gallego

São Paulo State University

58 PUBLICATIONS 199 CITATIONS

SEE PROFILE

Oscar Balancin

Universidade Federal de São Carlos

55 PUBLICATIONS 392 CITATIONS

SEE PROFILE

Some of the authors of this publication are also working on these related projects:

Materials processing using electron beam: cladding, surface alloying, hardening and additive manufacturing View project

Nanomaterials with applications in hydrogen production and storage View project 


\title{
Analysis of Recrystallization and Strain-Induced Precipitation on High $\mathrm{Nb}$ - and N-bearing Austenitic Stainless Steel
}

\author{
M.B.R. Silva ${ }^{1, a}$, J. Gallego ${ }^{2, b}$, J.M. Cabrera ${ }^{3,4, c}$, O. Balancin ${ }^{1, d}$ \\ and A.M. Jorge $\mathrm{Jr}^{1, \mathrm{e}}$ \\ ${ }^{1}$ Department of Materials Engineering, UFSCar, Via Washington Luis, Km 235, 13565-905 São Carlos, \\ SP, Brazil \\ ${ }^{2}$ Department of Mechanical Engineering, UNESP, Avenida Brasil, 56, 15385-000 Ilha Solteira, SP, Brazil \\ ${ }^{3}$ Department of Materials Science and Metallurgical Engineering, Polytechnic University of \\ Catalunya, Av. Diagonal 647, 08028 Barcelona, Spain \\ ${ }^{4}$ Fundacio CTM Centre Tecnologic, Av. Bases de Manresa 1, 08242 Manresa, Spain \\ amarianabdrs@gmail.com, bgallego@dem.feis.unesp.br, cjose.maria.cabrera@upc.edu, \\ dbalancin@ufscar.br, emoreira@ufscar.br
}

Keywords: Austenitic stainless steel, TEM, interaction precipitation-recrystallization

\begin{abstract}
The mechanical properties and corrosion resistance of stainless steels are due to the combined effect of chemical composition and thermomechanical processing. The objective of this study was to investigate the interaction precipitation-recrystallization of an austenitic steel with high additions of nitrogen and niobium through continuous-cooling multiple deformation hot-torsion tests. Samples were heated up to a soaking temperature of $1250{ }^{\circ} \mathrm{C}$ and kept at this temperature for 5 minutes, and then deformed during cooling. The deformation pass was 0.3 with a strain rate of $1 \mathrm{~s}^{-1}$ and interpass times of 20 or $50 \mathrm{~s}$. The evolution of the microstructure was investigated by optical, EBSD and transmission electron microscopy, using thin foils and carbon extraction replica samples. The results showed that some precipitates were not dissolved after reheating and the presence of niobium- and chromium-rich particles after processing was confirmed. The strain accumulation with the interpass time of $20 \mathrm{~s}$ yielded finer precipitation and improved grain refinement than observed after $50 \mathrm{~s}$. Some interaction of the precipitates with dislocations and grain boundary could be evidenced.
\end{abstract}

\section{Introduction}

Austenitic stainless steels have received considerable interest as orthopedic implant materials being the ISO 5832-1 steel (ASTM F 138) the most widely used in this type of application [1]. However, due to the low resistance in the annealed condition and the susceptibility to localized corrosion, a wider use of this type of steel in orthopedic applications is limited. The ISO 5832-1 steel has been gradually replaced by an austenitic stainless steel with high nitrogen and high niobium content according to ISO 5832-9 specification [2].

The mechanical and corrosion properties of these latter alloys are controlled by the precipitation of second phase particles. The presence of fine precipitates with small spacing between them tends to pinning the grain boundaries and inhibits the static and dynamic recrystallization, whereas the coarsening of these precipitates may deteriorate fatigue properties and corrosion resistance of the material [3].

The scientific features needed to control the microstructural evolution during thermomechanical processing of ISO 5832-9 steel are still unknown [4]. The knowledge and control of the kinetics of dissolution and subsequent precipitation during hot deformation and cooling can lead to microstructure refining or even strength increase due to a higher accumulation of 
dislocations, as in the case of microalloyed steels [5]. There is evidence that the precipitation of second phase particles in this steel is mainly composed by Z-phase $(\mathrm{CrNbN})$, but still the role of these nitrides in the plastic behavior during thermomechanical processing of this steel is not fully understood [6].

The Z-phase has been widely reported in the literature of martensitic stainless steels. It plays an important role in the resistance of these materials, but its formation kinetics and its real influence in softening processes, specifically in recrystallization, are unknown [7]. Also, it is not clear whether the particles are precipitated directly from the matrix or takes place by phase transformation from the diffusion of $\mathrm{Cr}$ in the matrix for nitride formation [8]. It is clear that with a better knowledge of the mechanical behavior of this material (ISO 5832-9 steel) during hot deformation, one can design thermomechanical schedules for forging or rolling, optimizing the mechanical, corrosion and especially the corrosion-fatigue properties.

\section{Materials and procedure}

The material used in this investigation was a high-niobium and high-nitrogen austenitic stainless steel whose chemical composition is given in Table 1. The steel had been previously hot rolled in the form of bars with $20 \mathrm{~mm}$ diameter, annealed at $1030{ }^{\circ} \mathrm{C}$ for $60 \mathrm{~min}$ and cooled in water. Cylindrical specimens with $5 \mathrm{~mm}$ effective radius and $10 \mathrm{~mm}$ length in the reduced central gage section were machined out of the bars. The mechanical tests were performed on a hot torsion machine, where the samples were heated in an induction furnace coupled to the machine. The temperature was measured using an optical pyrometer. Experimental data were collected by means of a software that also control the tests parameters such as temperature, strain rate, holding time and straining amount.

The interaction between recrystallization and precipitation was analyzed by hot torsion tests with multiple deformations during continuous cooling. The samples were heated from room temperature to a soaking temperature of $1250{ }^{\circ} \mathrm{C}$ and hold at that temperature for $5 \mathrm{~min}$. Then, the specimens were subjected to successive passes of true strain $(\varepsilon)$ of 0.3 and a constant strain rate of $1.0 \mathrm{~s}^{-1}$, while were cooled down continuously at a rate of $24{ }^{\circ} \mathrm{C} / \mathrm{min}$ or $60{ }^{\circ} \mathrm{C} / \mathrm{min}$. The interpass times $\left(\mathrm{t}_{\mathrm{ip}}\right)$ were 20 and $50 \mathrm{~s}$ and after the interruption of the deformation the samples were quenched in water.

The samples were characterized by optical microscopy, electron back scattered diffraction (EBSD) and transmission electron microscopy (TEM) (using thin foils and carbon extraction replica), and the microstructure was observed in the longitudinal plane, just below the deformed surface. The samples were polished and electrolytic etched with a solution of $\mathrm{HNO}_{3}(65 \%)$ for optical, EBSD and carbon replicas analysis. Thin foil samples were prepared by electrolytic polishing using a solution of acetic acid (95\%) and perchloric acid (5\%). TEM analyzes were performed on a FEI Tecnai G2 F20, operated at $200 \mathrm{kV}$. The size distributions were made by counting more than 200 precipitates or 400 grains for each sample analyzed.

Table 1. Chemical composition of austenitic stainless steel (\% weight)

\begin{tabular}{|c|c|c|c|c|c|c|c|c|c|c|c|c|c|}
\hline $\mathbf{C}$ & $\mathbf{S i}$ & $\mathbf{M n}$ & $\mathbf{N i}$ & $\mathbf{C r}$ & $\mathbf{M o}$ & $\mathbf{S}$ & $\mathbf{P}$ & $\mathbf{C u}$ & $\mathbf{N}$ & $\mathbf{N b}$ & $\mathbf{V}$ & $\mathbf{T i}$ & $\mathbf{F e}$ \\
\hline 0.031 & 0.38 & 3.98 & 10.43 & 20.43 & 2.46 & 0.0018 & 0.022 & 0.12 & 0.35 & 0.28 & 0.12 & 0.005 & bal. \\
\hline
\end{tabular}

\section{Results and Discussion}

The initial microstructure observed after soaking consists of coarse grains and twins, as shown in Figure 1(a). The average grain diameter (d) was $62 \mu \mathrm{m}$. In this micrograph, the grains 

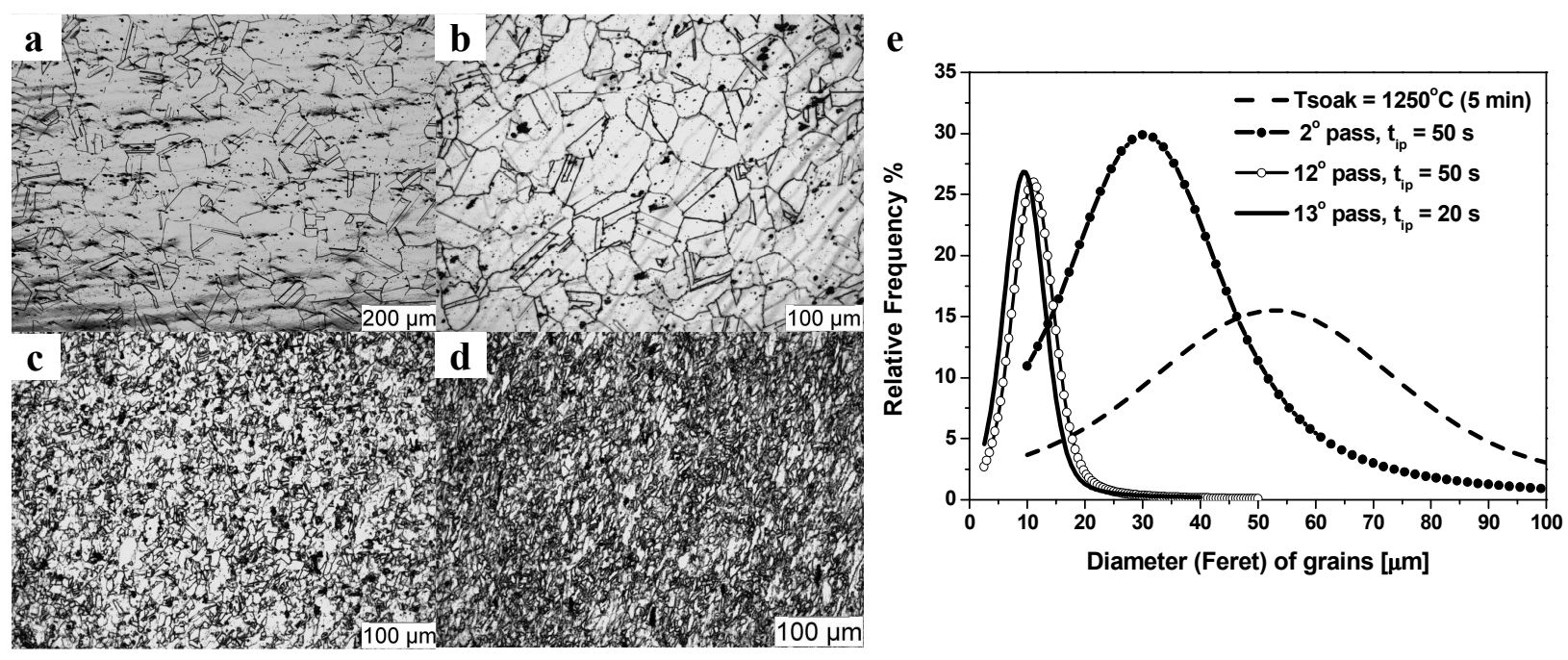

Figure 1. Optical micrographs: $\mathrm{T}_{\text {soak }}=1250{ }^{\circ} \mathrm{C}(5 \mathrm{~min})(\mathrm{a})$; on cooling with $\mathrm{t}_{\text {ip }}=50 \mathrm{~s}$ after 2 passes; (b) and after 12 passes (c); $t_{\text {ip }}=20 \mathrm{~s}$ after 13 passes (d). Statistical distribution of grain size (e).

have different sizes, indicating that some grain growth took place during soaking. It is also observed in this microstructure large number of coarse precipitates with different sizes, particularly inside the grains, that did not dissolve completely during reheating process.

Fig. 1(b) depicts grains after 2 passes of deformation with an interpass time of $50 \mathrm{~s}$, is possible to note that under this condition recrystallization was complete, presenting a grain size of $33 \mu \mathrm{m}$. Figures 1(c) and 1(d) show optical micrographs observed in samples where deformation was interrupted below the non-recrystallization temperature $\left(\mathrm{T}_{\mathrm{nr}}<1100{ }^{\circ} \mathrm{C}\right)$. Fig. $1(\mathrm{c})$ represents the sample after 12 passes of deformation and an interpass time of $50 \mathrm{~s}$, and Fig. 1(d) illustrate the microstructure after 13 passes with an interpass of $20 \mathrm{~s}$. Both microstructures are composed by recrystallized grains and the presence of deformed grains is still apparent, indicating an incomplete recrystallization. However a noticeable grain refinement was promoted. In Figure 1(e) dislays the grain size distribution, showing that the average grain size for the experiment with interpass times of $20 \mathrm{~s}(9.48 \mu \mathrm{m})$ was a little lower than that observed in the experiment with interpass times of $50 \mathrm{~s}$ $(11.05 \mu \mathrm{m})$.

Carbon replicas were made in order to analyze the precipitates without the interference of the austenitic matrix and to count the size of the precipitates. Micrographs in the Figure 2 show precipitates with different morphologies and sizes extracted by carbon replica of different test conditions but at the same magnification $(7000 \mathrm{X})$. Figure 2(a) was obtained after reheating to $1250{ }^{\circ} \mathrm{C}$ and it can be noted that the majority of the precipitates were dissolved. The average precipitate size was $133.03 \mathrm{~nm}$, the volume fraction $\left(f_{v}\right)$ of $1.6710^{-3}$ and density particles $(\rho)$ equal to 0.32 particles $/ \mu \mathrm{m}^{2}$. After 2 passes and an interpass time of $50 \mathrm{~s}$ (see Figure $2(\mathrm{~b})$ ), the average size of the precipitates increased to $153.85 \mathrm{~nm}$, presenting volume fractions and particle densities of $\mathrm{f}_{\mathrm{v}}=$ $4.9710^{-3}$ and $\rho=0.57$ particles $/ \mu \mathrm{m}^{2}$, It is worth noting that a little precipitation occurs even at elevated temperatures. Figure 2(c), which corresponds to the microstructure after 12 passes and interpass time of $50 \mathrm{~s}$, shows that precipitation was profuse. The average size of the precipitates was $48.87 \mathrm{~nm}$, and volume fractions and particles densities were $\mathrm{f}_{\mathrm{v}}=9.9210^{-3}$ and $\rho=16.12$ particles $/ \mu \mathrm{m}^{2}$. With the interpass time of $20 \mathrm{~s}$ and after the 13th pass (see Figure 2(d)), a large amount of precipitates is readily apparent, having an average size of $38.64 \mathrm{~nm}$, and volume fractions and particle densities of $\mathrm{f}_{\mathrm{v}}=6.2510^{-3}$ and $\rho=14.18$ particles $/ \mu \mathrm{m}^{2}$. The statistical distribution of the sizes of the precipitates is reported in Figure 1(e), where it can be seen that the precipitation is intense after $\mathrm{T}_{\mathrm{nr}}$. It is noticeable that with interpass time of $20 \mathrm{~s}$ the size of the precipitates was smaller than those observed after interpass time of $50 \mathrm{~s}$ and with larger volume fraction.

Figure 3(a) shows some precipitates after reheating the sample and the corresponding EDS spectrum of the particle indicated by an arrow. It is observed that the precipitates are coalescing and 


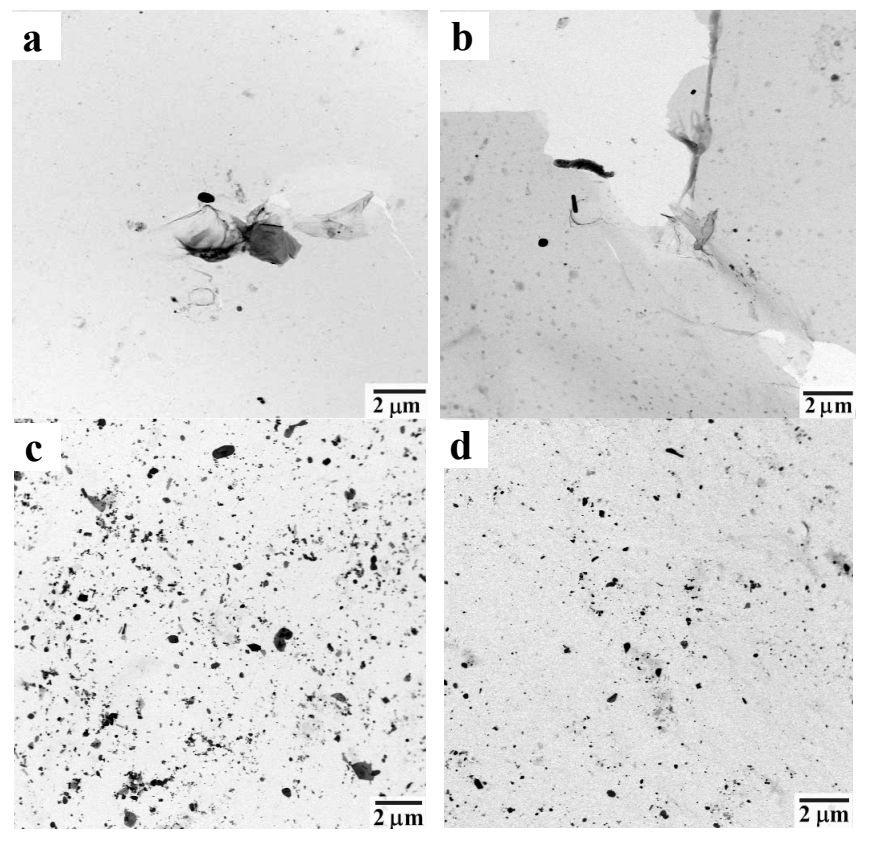

e

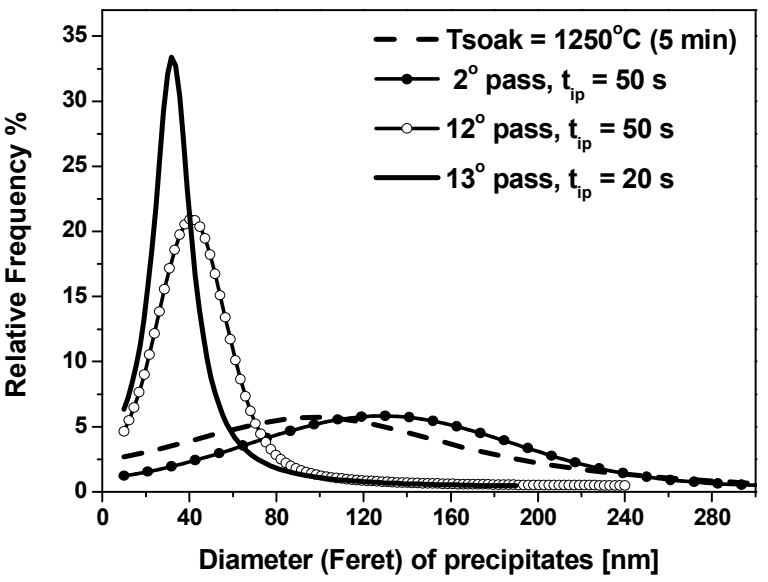

Figure 2. STEM micrographs of carbon replica: $\mathrm{T}_{\text {soak }}=1250{ }^{\circ} \mathrm{C}(5 \mathrm{~min})$ (a); on cooling with $\mathrm{t}_{\text {ip }}=50 \mathrm{~s}$ after 2 passes (b) and after 12 passes (c); $\mathrm{t}_{\mathrm{ip}}=20 \mathrm{~s}$ after 13 passes (d). Statistical distribution of precipitate size (e).

presents $\mathrm{Ti}$ in addition to $\mathrm{Cr}$ and $\mathrm{Nb}$ in their chemical composition. The large amount of $\mathrm{Cu}$ comes from the copper grid used as a support for the carbon film. Figure 3(b) corresponds to the sample analyzed after $\mathrm{T}_{\mathrm{nr}}$ and with interpass time of $20 \mathrm{~s}$ showing small particles $(<30 \mathrm{~nm})$, whose chemical analysis reveals that the Ti is not present, characterizing Z-phase precipitates.

EBSD analyses were made in order to observe the recrystallized volume fraction. Figure 4(a) shows the results of a sample with 2 passes and recrystallized fraction of the $80 \%$. Below $\mathrm{T}_{\mathrm{nr}}$ (Figures 4(b) and 4(c)), the recrystallization was retarded, observing a recrystallized fraction of approximately $65 \%$ for both samples (interpass time of 50 and $20 \mathrm{~s}$ ).

Thin foil TEM micrographs are shown in Figure 5. Figure 5(a) was obtained after soaking and it shows that most of the finer precipitates were dissolved, while the undissolved ones are very large $(>200 \mathrm{~nm})$.
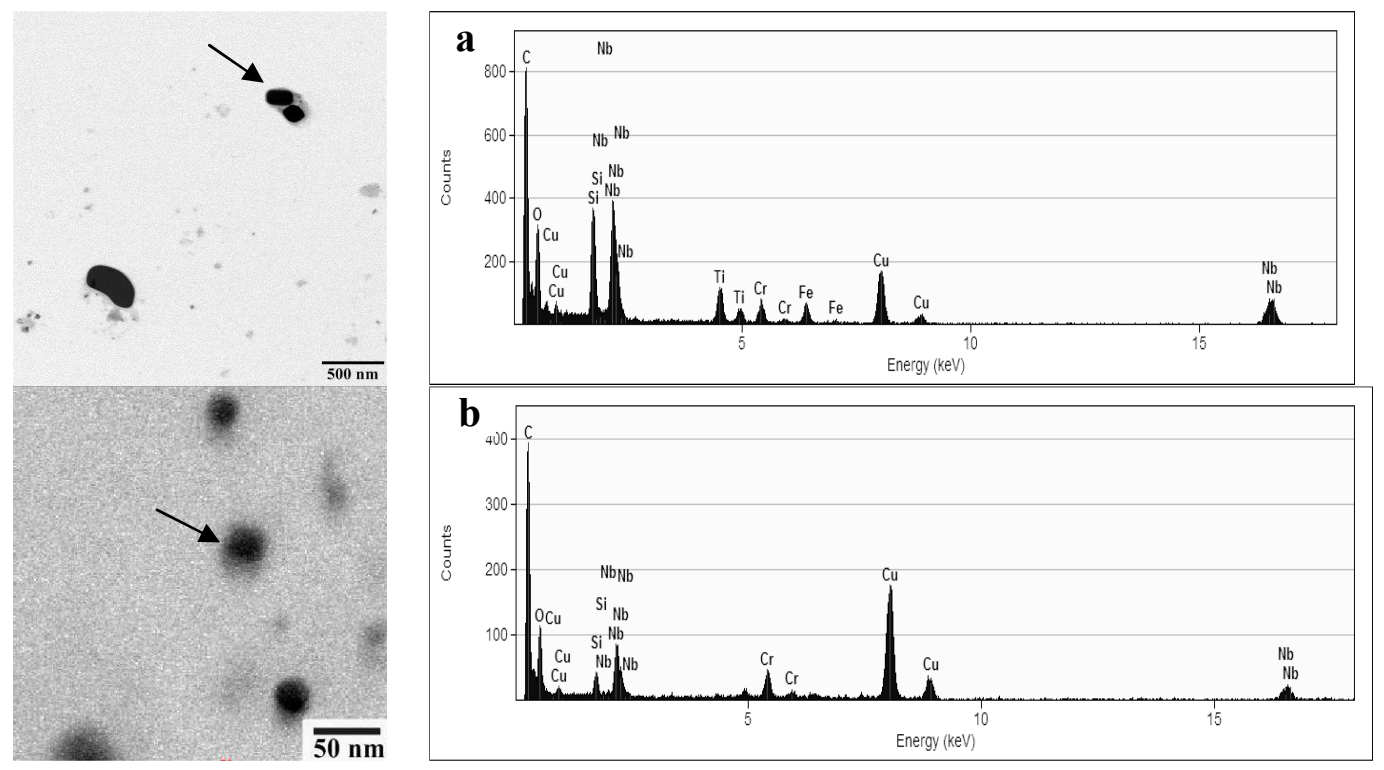

Figure 3. Bright field TEM image of carbon replica from a sample soaked at $\mathrm{T}_{\text {soak }}=1250{ }^{\circ} \mathrm{C}$ ( $5 \mathrm{~min}$ ) (a) and the sample with interpass time of $20 \mathrm{~s} \mathrm{(b).} \mathrm{The} \mathrm{EDS} \mathrm{spectrums} \mathrm{correspond} \mathrm{to} \mathrm{the}$ indicated particles. 

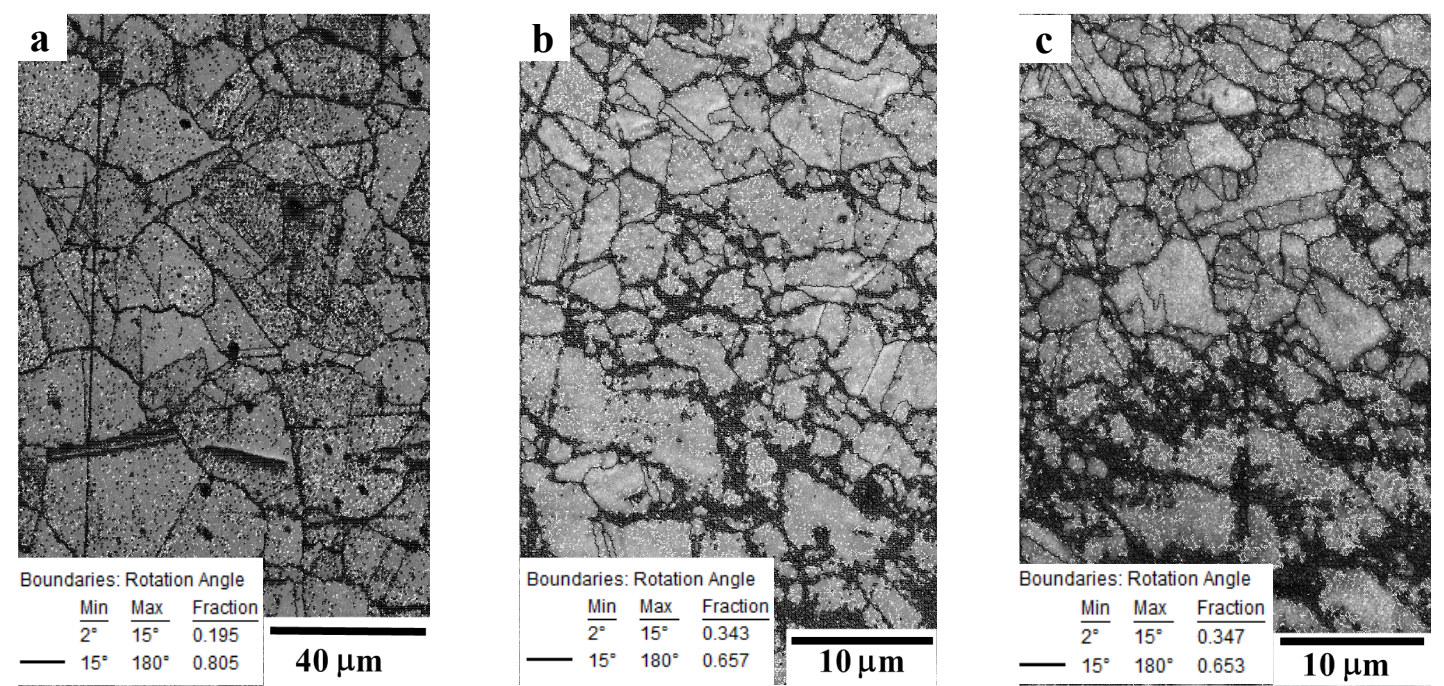

Figure 4. Grain boundary EBSD OIM maps: $t_{i p}=50 \mathrm{~s}$ after 2 passes (a); after 12 passes (b); and the sample with interpass time of $20 \mathrm{~s}$ (after 13 passes). Black lines indicates high-angle grain boundaries (> $15 \mathrm{deg})$. White lines shows low angle grain boundaries (2-15 deg).

The microstructure corresponding to the sample after two passes is shown in Figure 5(b), where one can note only the presence of large precipitates and free of dislocations. The micrographs of the last two figures correspond to the microstructures observed below the $T_{n r}$ where most of the precipitates are below $50 \mathrm{~nm}$ in diameter. The microstructure presented in Figure 5(c) was obtained after $50 \mathrm{~s}$ between passes, which results in a region already recrystallized, free of dislocations but with intense precipitation. Finally, figure 5(d) shows some particles interacting with dislocations in a subgrain.
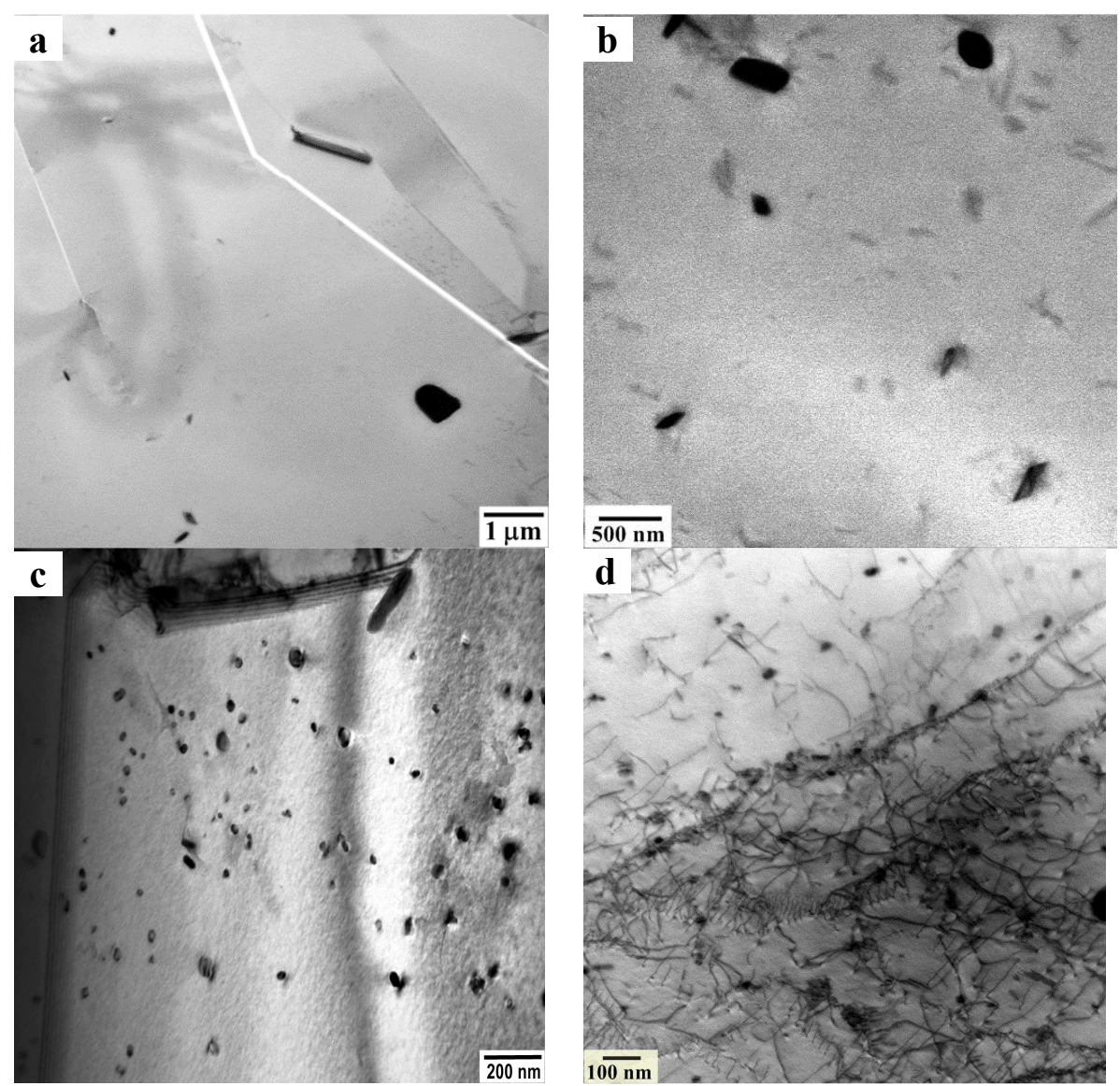

Figure 5. TEM analysis of thin foils: $\mathrm{T}_{\text {soak }}=1250{ }^{\circ} \mathrm{C}(5 \mathrm{~min})(\mathrm{a})$; on cooling with $\mathrm{t}_{\text {ip }}=50 \mathrm{~s}$ after 2 pass (b); 12 passes (c) and and with $t_{i p}=20 \mathrm{~s}$ after 13 passes (d). 
It is well known that in experimental multiple deformations continuous on cooling, the level of stress increases as a result of the temperature reduction. The retardation of recrystallization can occur by two striking effects: solute atoms $(\mathrm{Nb}, \mathrm{N}, \mathrm{Mo})$ and strain-induced precipitation which reduces the mobility of grain boundaries. As well the static recrystallization was not completed below $\mathrm{T}_{\mathrm{nr}}$ in all experiments conducted here, grain refinement took place. The grain size was reduced from $62 \mu \mathrm{m}$ to $11.05 \mu \mathrm{m}$ with interpass time of $50 \mathrm{~s}$ and to $9.48 \mu \mathrm{m}$ with $20 \mathrm{~s}$, after $\mathrm{T}_{\mathrm{nr}}$. In the sample of $50 \mathrm{~s}$ the volume fraction of precipitate was higher than in the interpass time of $20 \mathrm{~s}$, but with $20 \mathrm{~s}$ the amount of small precipitates was higher.

This set of results shows that with lower interpass times is possible the accumulation of deformations because of higher amount of precipitates smaller than $50 \mathrm{~nm}$, which can directly influence the process of recrystallization of the material providing significant grain refinement.

\section{Conclusions}

TEM analyses have allowed to conclude that fine second phase precipitation and grain refinement of austenitic grains took place during mechanical processing of ISO 5832-9 steel. The grain size refinement was improved with smaller interpass time. Large volume fraction of fine precipitates was obtained when interpass time and temperature were decreased, mainly below the non-recrystallization temperature $\mathrm{T}_{\text {nr. }}$ EBSD data have confirmed that the recrystallized fraction was higher at high temperatures than below $\mathrm{T}_{\mathrm{nr}}$. TEM analysis confirms that the precipitates are rich in niobium and chromium, typical elements of Z-phase. Thin foil samples investigation showed an intense precipitation in low temperatures, with evidence of interaction between precipitates and subgrains and dislocations in samples with lower interpass time.

\section{Acknowledgements}

The authors are grateful to $\mathrm{CNPq}$ (Conselho Nacional de Desenvolvimento Científico e Tecnológico) for the financial support received and Villares Metals, São Paulo, Brazil, that supplied the steel. As well authors are grateful to CNPq (Brazil) and Ministerio de Educacion (Spain) for funding a bilateral cooperation

\section{References}

[1] I. Gotman, Characteristics of metals used implants, Journal of Endourology. v.11, n.6 (1997) 383-389.

[2] J. Menzel, W. Kirschner, G. Stein, High nitrogen containing Ni-free austenitic steels for medical applications ISIJ International. v.36, n.7 (1996) 893-900.

[3] F. J. Humphreys, M. Hatherly, Recrystallization and related annealing phenomena. $2^{\mathrm{a}}$ Ed., Elsevier LTD, Oxford, 2004.

[4] E. J. Giordani, A. M. Jorge Jr, O. Balancin, Evidence of strain-induced precipitation on a Nband N-bearing austenitic stainless steel biomaterial, Materials Science Forum, 500-501 (2005) 179186.

[5] A. J. Deardo, Modern Thermomechanical Processing of Microalloyed Steel: A Physical Metallurgy Perspective. Microalloying'95 Conference Proceeding (Pittsburgh). TMS-AIME, Warrendale, (1995) 15-33.

[6] C. Örnhagen, J-O Nilsson, H.Vannevik, Characterization of a nitrogen-rich austenitic stainless steel used for osteosynthesis devices, Journal of Biomedical Materials Research, 31 (1996) 97-103.

[7] P. W. Robinson, D. H. Jack, Precipitation of Z-phase in a high-nitrogen stainless steel, J. Heat Treating. v.4, n.1 (1985) 69-74.

[8] H. K. Danielsen, J. Hald, On the nucleation and dissolution process of Z-phase $\mathrm{Cr}(\mathrm{V}, \mathrm{Nb}) \mathrm{N}$ in martensitic 12\%Cr steels, Materials Science and Engineering A. 505 (2009)169-177. 